\title{
Funding of Parkinson Research from Industry and US Federal and Foundation Sources
}

\author{
E. Ray Dorsey, MD, MBA, ${ }^{1 *}$ Joel P. Thompson, MPH, ${ }^{2}$ Mark Frasier, $\mathrm{PhD},{ }^{3}$ Todd Sherer, $\mathrm{PhD},{ }^{3}$ \\ Brian Fiske, $\mathrm{PhD},{ }^{3}$ Sean Nicholson, $\mathrm{PhD},{ }^{4} \mathrm{~S}$. Claiborne Johnston, $\mathrm{MD}, \mathrm{PhD},{ }^{5}$ \\ Robert G. Holloway, MD, MPH, ${ }^{1}$ and Hamilton Moses III, MD, ${ }^{6}$ \\ ${ }^{I}$ Department of Neurology, University of Rochester Medical Center, Rochester, New York, USA \\ ${ }^{2}$ School of Medicine, University at Buffalo School of Medicine \& Biomedical Sciences, Buffalo, New York, USA \\ ${ }^{3}$ Michael J. Fox Foundation for Parkinson's Research, New York, New York, USA \\ ${ }^{4}$ Department of Policy Analysis and Management, Cornell University, Ithaca, New York, USA \\ ${ }^{5}$ Department of Neurology, University of California, San Francisco, California, USA \\ ${ }^{6}$ The Alerion Institute, North Garden, Virginia, USA
}

\begin{abstract}
Funding for biomedical and neuroscience research has increased over the last decade but without a concomitant increase in new therapies. This study's objectives were to determine the level and principal sources of recent funding for Parkinson disease (PD) research and to determine the current state of PD drug development. We determined the level and principal sources of recent funding for PD research from the following sources: US federal agencies, large PD foundations based in the United States, and global industry. We assessed the status of PD drug development through the use of a proprietary drug pipeline database. Funding for PD research from the sources examined was
\end{abstract}

approximately $\$ 1.1$ billion in 2003 and $\$ 1.2$ billion in 2005 . Industry accounted for $77 \%$ of support from 2003 to 2005. The number of drugs in development for PD increased from 67 in 2003 to 97 in 2007. Of the companies with at least one compound in development for PD in 2007, most were small (62\% had annual revenue of less than $\$ 100$ million), and most $(53 \%)$ were based outside the United States. These companies will likely require partnerships to drive successful development of new PD therapies. (C) 2009 Movement Disorder Society

Key words: Parkinson disease; biomedical research; drug development
Funding for biomedical research as a whole has grown dramatically over the past decade. ${ }^{1,2}$ Within neurosciences, funding increased from $\$ 4.8$ billion in 1995 to $\$ 14.1$ billion in 2005 . $^{3}$ However, the increase in funding has not been accompanied by a rise in the

The views expressed in the article reflect those of the authors alone and do not necessarily reflect those of any funding organization.

*Correspondence to: E. Ray Dorsey; 1351 Mt. Hope Ave., Suite 223, Rochester, New York 14620.

E-mail: ray.dorsey@ctcc.rochester.edu

Potential conflict of interest: The Michael J. Fox Foundation supported this research. Drs. Frasier, Fiske, and Sherer, Co-authors of the manuscript, are employees of the Michael J. Fox Foundation. Dr. Dorsey holds stock options in Avid Radiopharmaceuticals, Inc., which had no role in this manuscript.

Received 15 May 2008; Revised 11 September 2008; Accepted 2 December 2008

Published online 9 January 2009 in Wiley InterScience (www. interscience.wiley.com). DOI: 10.1002/mds.22446 number of new drugs approved by the US Food and Drug Administration (FDA). The number of approvals for all neuroscience drugs and for new molecular entities, compounds that contain an active ingredient that has never been marketed in the United States, has largely been stagnant over the last decade ${ }^{1,3}$ and has raised questions about the productivity of biomedical research. $^{3-5}$ The recent constraints on National Institutes of Health (NIH) funding of biomedical research ${ }^{6}$ and cutbacks within the pharmaceutical industry ${ }^{7}$ all heighten concerns about prospects for growth in funding for biomedical research. Against this backdrop, the need to allocate resources efficiently and effectively will likely grow.

Parkinson disease (PD) is the second most common neurodegenerative condition whose US and global burden will grow over the next generation. ${ }^{8}$ Since 1995 , at least 10 new drugs (pramipexole, ropinirole, tolca- 
pone, entacapone, apomorphine, rasagiline, selegiline, carbidopa/levodopa/entacapone, selegiline sublingual, and rotigotine) have been approved in the United States for an indication related to PD. ${ }^{3,9-12}$ These drugs have benefited people with PD, but most of the gain has been incremental with critiques focusing on their "diminishing therapeutic returns."13 To help address the need to maximize the value of resources devoted to $\mathrm{PD}$, we sought to determine the level and principal sources of recent funding for PD research and to determine the current state of PD drug development.

\section{METHODS}

\section{Therapeutic Pipeline for PD}

We used a proprietary database (Pharmaprojects) ${ }^{14}$ to identify therapies in development for PD for 2003 through 2007. Pharmaprojects contains data on more than 7,000 drug candidates in active development, including target indication, progress to date, and commercial history of the compound and is commonly used by industry, financial services firms, and researchers to track drug development. We identified compounds (small molecules and biologics) in development for PD as having a therapy description of "antiparkinsonian." We also included stem cell and gene therapies that had antiparkinsonian listed as an indication. We then excluded compounds from the list with "primary therapy" and "primary pharmacology" descriptions that were inconsistent with compounds targeted for PD (e.g., treatments for multiple sclerosis). We restricted our analysis to those compounds that were in development from the preclinical stage to phase III. One compound listed only as "clinical trial" was assumed to be in phase I. The years for which the drug development status was missing were filled using the development status from the prior years ( $\mathrm{n}=7$ compounds).

For each compound in development, we identified the company that was listed as its "originator." Each company's home country was identified from the Pharmaprojects database. Revenue for fiscal year 2007 was obtained from publicly available information on the US Securities and Exchange Commission website (forms $10-\mathrm{K}$ or $20-\mathrm{F})(\mathrm{n}=24),{ }^{15}$ annual reports on company websites $(n=27)$, or Hoover's business database $(\mathrm{n}=18) .{ }^{16}$ If a firm was owned by a parent company, revenues from the parent company were used. Fiscal year 2007 revenues were converted to US dollars based on the exchange rates ${ }^{17}$ on March 31, 2007 (end of fiscal year when most annual reports were published).
To assess the progression of drugs in development, we evaluated the drugs listed in development in Pharmaprojects in 2003 to see whether they were still in development in 2007 and whether their phase of development had progressed. We used a 4-year lag period as this length approximates the phase with the longest duration (39 months for phase II) for neurological drug development. ${ }^{18}$ We compared the rate of progression (likelihood of a drug advancing from one phase to the next phase, such as from phase II to phase III) to published estimates for the likelihood of advancement for neurological diseases as a whole. ${ }^{18}$

\section{Funding for PD Research}

To estimate the annual research costs associated with developing each compound, we used published estimates for research costs for each phase of development (\$15.2 million for phase I, \$23.5 million for phase II, and $\$ 86.3$ million for phase III) and adjusted them to account for the different duration of investigation (1.8 years for phase I, 2.1 years for phase II, and 2.5 years for phase III) to obtain annual estimates for research costs at each phase $(\$ 8.4$ million annual development cost for Phase I, $\$ 11.0$ million for Phase II, and $\$ 34.0$ million for Phase III). ${ }^{19,20}$ We excluded costs due to long-term animal testing during clinical development. The annual preclinical research costs (\$6.8 million) were estimated using the average costs from two published studies. ${ }^{19,20}$ We excluded compounds $(n=6)$ that were sponsored by nonprofit institutions, such as the NIH (whose research support was captured directly) or universities.

For the medical device industry, we identified the company with the largest market share for deep brain stimulation (Medtronic) and allocated its research and development budget in proportion to its sales of devices for PD-based on data from its Security and Exchange Commission filing. ${ }^{21}$

As part of a larger assessment of the landscape of funding for PD, we obtained US federal estimates for research support for PD from 2003 through 2005 from the NIH and the Department of Defense through a direct request (Directors of each Institute at the NIH, Stephen Grate, DOD, personal communication). Some of these data are available publicly through either websites $^{22}$ or publicly accessible databases. ${ }^{23}$ We similarly solicited such data from four large PD foundations based in the United States (Parkinson's Disease Foundation, American Parkinson Disease Association, National Parkinson Foundation, Michael J. Fox Foundation for Parkinson's Research) through a direct 
TABLE 1. Funding for Parkinson disease research, 2003 to 2005 (in millions of US dollars)

\begin{tabular}{|c|c|c|c|}
\hline Source & 2003 & 2004 & 2005 \\
\hline US-based foundations & $\$ 15$ & $\$ 22$ & $\$ 20$ \\
\hline US Federal Government* & $\$ 261$ & $\$ 224$ & $\$ 236$ \\
\hline Industry & $\$ 785$ & $\$ 882$ & $\$ 948$ \\
\hline Total & $\$ 1,061$ & $\$ 1,128$ & $\$ 1,204$ \\
\hline
\end{tabular}

*Includes the US National Institutes of Health and the Department of Defense.

request (Robin Elliott, personal communication; Joel Gerstel, personal communication, date; Jose Garcia Pedrosa, personal communication; Deborah Brooks, personal communication). Importantly, this analysis did not include support from government and foundation sources outside the United States.

\section{RESULTS}

Funding for PD research from industry worldwide, the US federal government, and US-based foundations grew from $\$ 1.1$ billion in 2003 to $\$ 1.2$ billion in 2005 (Table 1). Of the sources examined, industry was the largest sponsor, accounting for $77 \%$ of total funding from 2003 to 2005. Funding from US-based foundations increased from \$15 million in 2003 to \$20 million in 2005.

The number of compounds in the PD development pipeline increased from 67 in 2003 to 97 in 2007 (Fig. 1). The growth was largely due to an increase in the number of preclinical compounds, which increased by $65 \%$ and comprised the majority $(63 \%)$ of compounds in development in 2007.

The number of companies developing compounds for PD increased from 53 in 2003 to 80 in 2007, with no company sponsoring more than three different com-

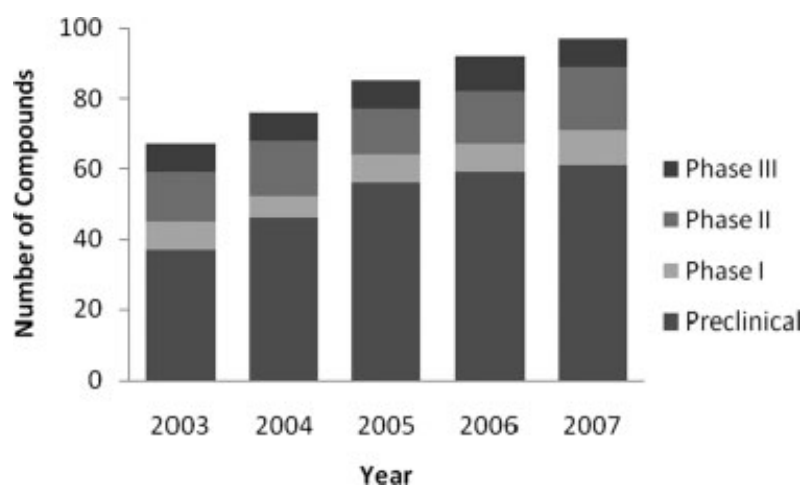

FIG. 1. Number of compounds in development for Parkinson disease by phase of development, 2003-2007.

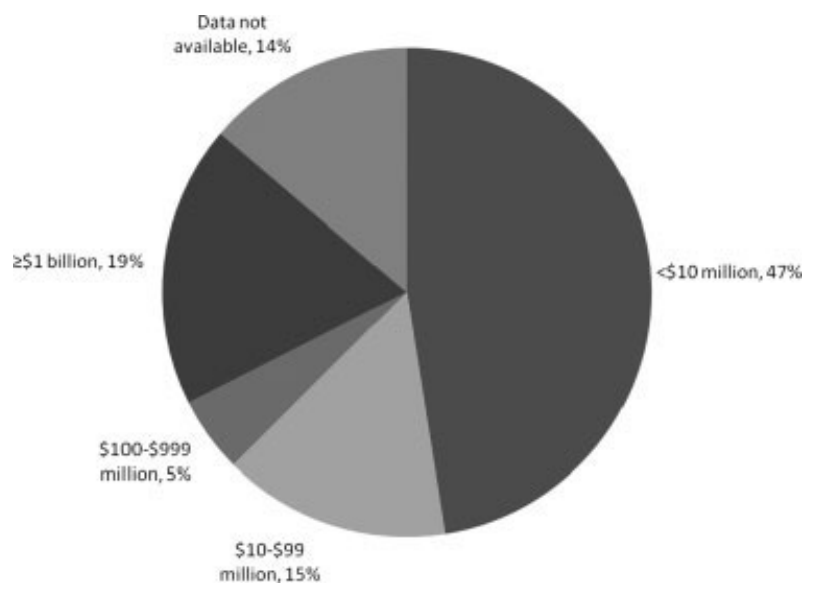

FIG. 2. Size of companies with at least one compound in development for Parkinson disease in 2007 by fiscal year 2007 revenue. $100 \%=80$ companies.

pounds. Fifty-nine $(74 \%)$ of the 80 companies entered the market between 2003 and 2007. Financial information was available for $69(86 \%)$ of the 80 companies. As measured by 2007 revenue, most of the companies with compounds in development were small (Fig. 2). Forty-seven percent had revenue of less than $\$ 10$ million and an additional $15 \%$ had revenue between $\$ 10$ and $\$ 100$ million. More than half (53\%) of the companies with at least one compound in development in 2007 were based outside the United States (Fig. 3).

Of the 67 compounds in development in 2003, 13 compounds had advanced in development by 2007

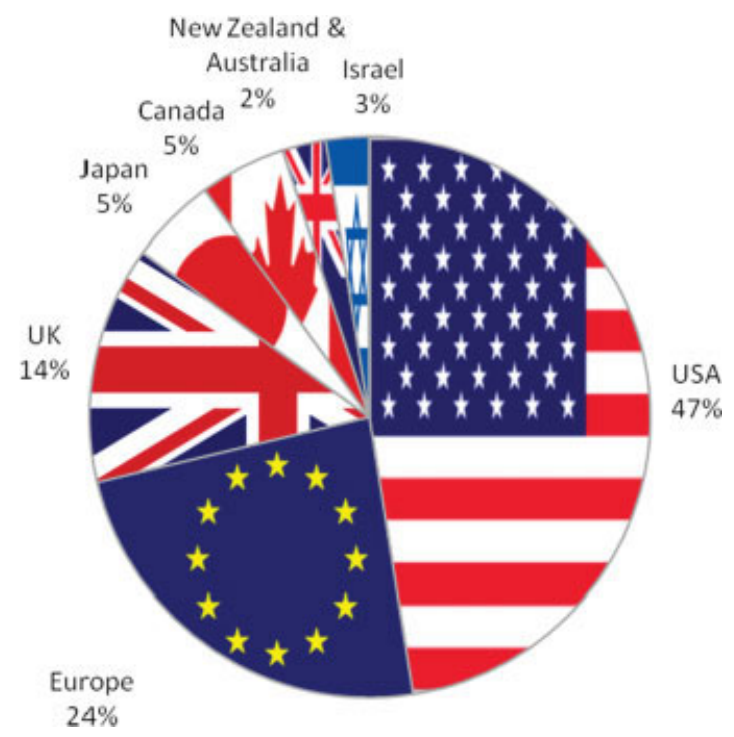

FIG. 3. Companies with at least one compound in development for Parkinson disease in 2007 by country. $100 \%=80$ companies. [Color figure can be viewed in the online issue, which is available at www.interscience.wiley.com.] 
TABLE 2. Advancement of compounds in development for Parkinson disease from 2003 to 2007

\begin{tabular}{lcccc}
\hline $\begin{array}{l}\text { Development } \\
\text { phase }\end{array}$ & $\begin{array}{c}\text { Number of compounds } \\
\text { in development in 2003 }\end{array}$ & $\begin{array}{c}\text { Number that had advanced } \\
\text { in development by 2007 }\end{array}$ & $\begin{array}{c}\text { Percent that had advanced } \\
\text { in development by 2007 }\end{array}$ & $\begin{array}{c}\text { Likelihood of advancement for } \\
\text { neurological drugs as a whole }\end{array}$ \\
\hline Preclinical & 37 & 3 & $8 \%$ & NA \\
Phase I & 8 & 3 & $38 \%$ & $73 \%$ \\
Phase II & 14 & 3 & $21 \%$ & $41 \%$ \\
Phase III & 8 & 4 & $50 \%$ & $22 \%$ \\
Total & 67 & 13 & $19 \%$ & NA \\
\hline
\end{tabular}

NA, Not Available.

(Table 2). An additional eight compounds remained in the same stage of development and may yet advance. The proportion of drugs advancing to the next phase of development varied from state to stage. Three $(8 \%)$ of the 37 preclinical compounds in development in 2003 had advanced into clinical development by 2007. Four (50\%) of the eight compounds in Phase III in 2003 had advanced to market entry by 2007 .

\section{DISCUSSION}

Funding for PD research from industry and USbased foundations and the US federal government exceeds $\$ 1$ billion annually. As is the case for biomedical and neuroscience research generally, industry rather than the US federal government is the principal sponsor of PD research and development. However, most of this research support is not from large pharmaceutical companies, as is the case for biomedical research as a whole ${ }^{1}$ or neuroscience generally. ${ }^{3}$ Less than $20 \%$ of the companies with compounds in development for PD had revenue exceeding a billion dollars, an amount typically associated with sales of a single "blockbuster" drug. This research support is coming from small, in some cases very small, privately held biotechnology firms-more than half of which are located outside the United States.

Smaller companies are unlikely to have the scale, resources, or expertise to drive the development of therapeutics for PD alone and consequently have high turnover, which may impede the overall development of new therapies. Generally, companies with less experience in developing drugs have lower rates of success for advancing a drug through each phase of development. $^{24}$ Smaller companies often license out compounds to larger companies as the compounds progress through drug development; ${ }^{24}$ however, the limited data on licensees available in Pharmaprojects suggests that only nine of the 36 compounds in clinical development (phase I through phase III) for PD in 2007 had been licensed to another company. The emergence of the role of smaller companies in drug development likely reflects the relative shift of large pharmaceutical research expenditures away from pre-clinical research. From 1994 to 2003, the proportion of large pharmaceutical research and development expenditures that went to preclinical research fell from 57 to $32 \% .^{1}$ In its place, large pharmaceutical companies shifted their expenditures to clinical and post-marketing studies, which rose from $5 \%$ of expenditures to $11 \%$ over the same time period. ${ }^{1}$

Drug development is costly, long, and risky. To develop a drug once it enters clinical trials (Phase I) costs between $\$ 500$ million to more than $\$ 2$ billion and takes 7 to 8 years. ${ }^{18}$ To our knowledge, no published data on costs and time to develop drugs specific for PD is available. However, published reports indicate that the clinical development of drugs with an Alzheimer disease indication takes 72 months when compared with 93 months for rheumatoid arthritis and 63 months for HIV/AIDS. ${ }^{18}$ Drug development is also uncertain. The probability of a drug successfully entering the next phase of development varies considerably by therapeutic area. For example, the likelihood of a drug successfully completing Phase II and entering Phase III ranges from 31 to $67 \% .^{18}$ In this study, the advancement rate of drugs in development for PD was quite variable (likely due in part to the small sample size) compared to published estimates for all neurological diseases (Table 2).

For symptomatic treatment, models for PD are welldeveloped and the regulatory pathway is clear as evidenced by the large number of recently approved treatments for PD. For disease modifying treatments, the path is less clear ${ }^{25}$ and faces several challenges, including the lack of a reliable animal model to predict clinical response in humans, the absence of biomarkers that correlate well with clinical measures, and the subjectivity of endpoints commonly used in PD trials. The lack of an animal model with predictive validity for neuroprotective/disease modifying therapies has resulted in several compounds that have demonstrated 
success in pre-clinical models but have failed clinically ${ }^{26,27}$ In the absence of a preclinical tool that can be used to predict the efficacy of a putative therapy, pharmaceutical and clinical investigators face additional uncertainty in deciding whether to advance a therapy into expensive clinical trials. ${ }^{26}$

Without reliable animal models, biomarkers can be especially helpful in screening promising compounds. However, the PD field does not currently have such markers. ${ }^{28}$ Imaging modalities to date have shown utility in differentiating those with a dopaminergic deficit versus those without but have not shown utility in demonstrating improvement that correlates with clinical measures. ${ }^{29,30}$ Peripheral biomarkers that reflect drug activity or provide evidence of a drug's mechanism of action are also largely missing in PD as are markers that can assess a drug's penetration of the blood brain barrier.

The lack of valuable biomarkers in PD increases the importance of the clinical endpoints used in PD. Unfortunately, many endpoints currently used (e.g., patient diaries) are subjective although efforts are underway to improve them. ${ }^{31}$ The absence of objective endpoints in clinical trials may lead to higher failure rates. ${ }^{32}$ In addition, because of its course, PD often requires clinical trials with long durations. Perhaps reflecting the progressive nature of many neurological conditions, drug development costs are higher and duration longer for neurological disorders than for infectious diseases, for example. ${ }^{18}$

To meet these challenges and to address the limited resources and capabilities of smaller companies, additional partnerships with academia, governments, large pharmaceutical firms, foundations, and other entities will likely be required to drive the development of PD therapies. Novel models for collaboration among industry, academia, foundations, and government exist. Among them are the Myelin Repair Foundation, which has a unique business/science model narrowly focused on developing new treatments for multiple sclerosis rapidly, and the Alzheimer's Disease Neuroimaging Initiative, the largest $\mathrm{NIH}$-private partnership in brain research that involves NIH, FDA, and several foundations and pharmaceutical companies with a common aim of developing imaging biomarkers to measure cognitive decline. ${ }^{33}$ Abroad, large pharmaceutical companies, such as GlaxoSmithKline, have formed partnerships with government funders and academic institutions, such as University College London, to identify and develop treatments for Creutzfeldt-Jacob disease. ${ }^{33}$ Foundations, with their ability to overcome traditional barriers and strike alliances among universities, investi- gators, and companies, may play an especially important role. ${ }^{34}$ In $\mathrm{PD}$, foundations have begun recognizing the limitations of some of the smaller companies driving PD drug development and have programs in place to support these companies. ${ }^{35}$ Additionally, broader efforts that more closely join smaller companies and their compounds, investigators and their expertise, and foundations and their resources and ability to bring in additional partners (e.g., large pharmaceutical companies, public funders, private individuals) may catalyze future progress in developing treatments for PD. In particular, PD may benefit from alliances and investment aimed at validation of drug discovery and development tools, such as biomarkers, in vitro validation techniques, and small proof of principle clinical trials.

This study was limited by data constraints because only limited information is available publicly. Our analysis only included US federal (NIH and Department of Defense) and foundation support while the analysis of industry support extended abroad. The estimates for the financing of PD research excluded many additional sponsors, including government and foundation support outside the United States, other US federal and state agencies, universities, private organizations, and individuals. However, the largest US funders of biomedical research ${ }^{1}$ (industry and NIH) were included in the study. The funding data were also limited by the absence of actual industry data on research and development support for PD. We, therefore, estimated research support based on published estimates of the average annual cost of supporting a compound at each stage of development because most companies, even many large ones, do not report research and development expenditures by disease area. The data on compounds in development for PD is also likely incomplete. The database (Pharmaprojects) that we used relies on multiple sources (e.g., public filings, press releases, conference presentations) but is neither perfect nor exhaustive. For example, Pharmaprojects' designation of compounds in development as anti-parkinsonian may not be accurate (e.g., drug is actually in development for an indication other than PD). In addition, early stage compounds, especially at large pharmaceutical companies, may not be readily identified and thus may be underrepresented in the database. The limitations on the identification of compounds also carry over to estimates on industry support for PD research. For example, to the extent that pre-clinical compounds are not captured by Pharmaprojects, industry support will be underestimated. Finally, data on licensing of compounds to large pharmaceutical companies is likely incomplete and may not always be 
current. Despite its limitations, the database is extensive and widely used by economists, ${ }^{36}$ industry experts, ${ }^{32}$ and government agencies ${ }^{18}$ examining drug development.

The therapeutic pipeline, especially preclinical compounds, for PD is growing, and the development of these therapies rests in the hands of small companies with limited resources. Global partnerships that capitalize on the expertise of investigators, the resources of government and foundations, and the active participation of patients will likely be required to foster the successful development of new treatments for PD.

Acknowledgments: We thank Ms. Deborah Brooks from the Michael J. Fox Foundation for Parkinson's Research, Mr. Robin Anthony Elliott from the Parkinson's Disease Foundation, Mr. Joel Gerstel from the American Parkinson Disease Association, and Ms. Pamela Olmo from the National Parkinson Foundation for their assistance in providing funding data. The Michael J. Fox Foundation for Parkinson's Research supported this research. Drs. Frasier, Sherer, and Fiske are all employees of the Michael J. Fox Foundation for Parkinson's Research. Dr. Holloway was supported in part by a K24 NS4 2098 from the National Institute of Neurological Disorders and Stroke. This publication was also made possible in part by Grant Number 1 UL1 RR024160-01 from the National Center for Research Resources (NCRR), a component of the National Institutes of Health (NIH), and the NIH Roadmap for Medical Research. Its contents are solely the responsibility of the authors and do not necessarily represent the official view of NCRR or NIH. Information on NCRR is available at http://www.ncrr.nih.gov/. Information on Re-engineering the Clinical Research Enterprise can be obtained from http:// nihroadmap.nih.gov/clinicalresearch/overview-translational. asp.

Author Roles: Research project: Conception - Dorsey, Frasier, Sherer, Fiske, Moses; Organization - Dorsey, Frasier; Execution - Dorsey, Thompson, Frasier, Sherer, Fiske, Nicholson, Johnston, Holloway, Moses. Statistical/data analysis: Design - Dorsey, Thompson, Frasier, Sherer, Fiske, Nicholson, Johnston, Holloway, Moses; Execution - Dorsey, Thompson, Frasier; Review and critique - Sherer, Fiske, Nicholson, Johnston, Holloway, Moses. Manuscript: Writing of the first draft - Dorsey, Thompson, Frasier; Review and critique - Sherer, Fiske, Nicholson, Johnston, Holloway, Moses.

\section{REFERENCES}

1. Moses H, Dorsey ER, Matheson DHM, Thier SO. Financial anatomy of biomedical research. JAMA 2005;294:1333-1342.

2. Connelly E, Propst S. 2006 Investment in US Health Research. Research!America 2007. Available at: http://www.researchamerica.org/uploads/healthdollar2006.pdf. Accessed August 24, 2008.

3. Dorsey ER, Vitticore P, de Roulet J, et al. Financial anatomy of neuroscience research. Ann Neurol 2006;60:652-659.
4. Booth B, Zemmel R. Prospects for productivity. Nat Rev Drug Discov 2004;3:451-457.

5. Mervis J. Productivity counts-But the definition is key. Science 2005;309:726-727.

6. Zerhouni EA. Research funding - NIH in the post-doubling era: realities and strategies. Science 2006;314:1088-1090.

7. Martinez B, Goldstein J. Big Pharma Faces Grim Prognosis. The Wall Street Journal December 6, 2007;A1.

8. Dorsey ER, Constantinescu R, Thompson JP, et al. Projected number of people with Parkinson disease in the most populous nations, 2005 through 2030. Neurology 2007;68:384-386.

9. US Food and Drug Administration. FDA Approved Drug Products. Available at: http://www.accessdata.fda.gov/scripts/cder/ drugsatfda/. Accessed January 28, 2008.

10. US Food and Drug Administration. Center for Drug Evaluation and Research Drug and Biologic Approval Reports. Available at: http://www.fda.gov/cder/rdmt/default.htm. Accessed September $10,2008$.

11. US Food and Drug Administration. FDA Drug Approvals List. Available at: http://www.fda.gov/cder/da/da.htm. Accessed September 10, 2008.

12. US Food and Drug Administration. FDA Drug and Device Product Approvals. Available at: http://www.fda.gov/cder/da/ddpa. htm. Accessed September 10, 2008.

13. Ahlskog JE. Beating a dead horse-Dopamine and Parkinson disease. Neurology 2007;69:1701-1711.

14. Pharmaprojects. Pharmaprojects-tracking global pharma R\&D since 1980. Available at: http://www.pjbpubs.com/pharmaprojects/index.htm. Accessed September 10, 2008.

15. US Securities and Exchange Commission. EDGAR Company Search. Available at: http://www.sec.gov/edgar/searchedgar/companysearch.html. Accessed September 11, 2008.

16. Hoovers. Hoovers 2008. Available at: URL: http://www.hoovers.com. Accessed January 25, 2008.

17. Bank of Canada. Exchange rates. Available at: http://www. bankofcanada.ca/en/rates/exchform.html. Accessed December 17, 2007.

18. Adams CP, Brantner VV. Estimating the cost of new drug development: Is it really $\$ 802$ million? Health Affairs 2006;25:420428.

19. Verkman AS. Drug discovery in academia. Am J Physiol Cell Physiol 2004;286:C465-C474.

20. DiMasi JA, Hansen RW, Grabowski HG. The price of innovation: new estimates of drug development costs. J Health Econ 2003;22:151-185.

21. US Securities and Exchange Commission. SEC Filings \& Forms (EDGAR). Available at: http://www.sec.gov/edgar.shtml. Accessed Septemeber 10, 2008.

22. National Institutes of Health. Estimates of Funding for Various Diseases, Conditions, Research Areas. Available at: http://www. nih.gov/news/fundingresearchareas.htm. Accessed September 11, 2008.

23. National Institutes of Health. CRISP. Available at: http://crisp. cit.nih.gov/. Accessed April 30, 2008.

24. Danzon PM, Nicholson S, Pereira NS. Productivity in pharmaceutical-biotechnology R\&D: the role of experience and alliances. J Health Econ 2005;24:317-339.

25. Kieburtz K, Ravina B. Why hasn't neuroprotection worked in Parkinson's disease? Nat Clin Pract Neurol 2007;3:240-241.

26. Olanow CW, Schapira AHV, Lewitt PA, et al. TCH346 as a neuroprotective drug in Parkinson's disease: a double-blind, randomised, controlled trial. Lancet Neurol 2006;5:1013-1020.

27. Shoulson I, Schwid S, Hyson C, et al. Mixed lineage kinase inhibitor CEP-1347 fails to delay disability in early Parkinson disease. Neurology 2007;69:1480-1490.

28. Michell AW, Lewis SJG, Foltynie T, Barker RA. Biomarkers and Parkinson's disease. Brain 2004;127:1693-1705.

29. Ravina B, Eidelberg D, Ahlskog JE, et al. The role of radiotracer imaging in Parkinson disease. Neurology 2005;64:208-215. 
30. Fahn S, Shoulson I, Kieburtz K, et al. Levodopa and the progression of Parkinson's disease. N Engl J Med 2004;351:2498-2508.

31. Goetz CG, Fahn S, Martinez-Martin P, et al. Movement disorder society-sponsored revision of the unified Parkinson's disease rating scale (MDS-UPDRS): Process, format, and clinimetric testing plan. Movement Disord 2007;22:41-47.

32. Elias T, Gordian M, Singh N, Zemmel R. Why products fail in phase III. In Vivo 2006;20:49-57.

33. Johnston SC, Hauser SL. A status report on neuroscience research, without grade inflation. Ann Neurol 2006;60:9A-11A.
34. Moses H, Martin JB. What should be done to improve the productivity of neurological research? Ann Neurol 2006;60:647651.

35. The Michael J Fox Foundation for Parkinson's Research. MJFF Funding Portfolio. Available at: http://www.michaeljfox.org/ research_MJFFfundingPortfolio.cfm. Accessed August 29, 2008.

36. Higgins MJ, Rodriguez D. The outsourcing of R\&D through acquisitions in the pharmaceutical industry. J Financ Econ 2006; 80:351-383. 